\title{
PROPOSTA DE GESTÃO DE ESTOQUE PARA UMA EMPRESA VAREJISTA EM ILHÉUS-BA
}

\section{PROPOSAL FOR INVENTORY MANAGEMENT FOR A RETAILER IN ILHEUS-BAHIA}

\author{
Caroline Santa Rosa Souza ${ }^{1}$; Meire Ramalho de Oliveira ${ }^{2}$ \\ ${ }^{1}$ Universidade Estadual de Santa Cruz - UESC - Ilhéus/BA - Brasil \\ carolinesrsouza@gmail.com \\ 2 Universidade Estadual de Santa Cruz - UESC - Ilhéus/BA - Brasil \\ moliveira@uesc.br
}

\begin{abstract}
Resumo
O setor varejista engloba diversas subdivisões, entre elas, o setor de vestuário, que envolve variáveis como tendências de moda e sazonalidade, que influenciam diretamente na compra e venda dos produtos, e gera reflexos na tomada de decisões dentro da empresa e na gestão de estoques. Entretanto, muitas micro e pequenas empresas varejistas não possuem um sistema de informação com módulos decisórios ou ainda de um sistema de gestão de estoque. Dessa forma, o presente artigo objetivou apresentar uma proposta para a gestão de estoques por meio das ferramentas de controle de estoque em uma empresa varejista na cidade Ilhéus-BA de forma a garantir uma vantagem competitiva. A pesquisa se deu a partir do estudo do perfil da empresa e da coleta de dados, os quais foram tratados por meio do conjunto de ferramentas de controle de estoque: Curva ABC, Giro de Estoque e Diagrama de Pareto. Os resultados foram analisados de modo a estabelecer uma gestão de estoque que impactassem na estratégia competitiva de mercado. Percebeu-se que a falta de gestão contribuiu para acúmulo de alguns itens, depreciação dos produtos e também para má distribuição do capital da empresa. A elaboração de uma proposta de gestão de estoque pode contribuir para o desenvolvimento dessas micro e pequenas empresas varejistas, por meio de um melhor direcionamento e suporte, contribuindo também para uma maior taxa de sobrevivência, e consequentemente para o desenvolvimento econômico e social do país.
\end{abstract}

Palavras-chave: gestão de estoque; ferramentas de controle de estoque; seleção de fornecedores; previsão de demanda; estoque mínimo e ressuprimento

\section{Introdução}

Atualmente, as atividades desenvolvidas dentro do setor de comércio e serviços configuramse como uma das mais relevantes atividades econômicas desenvolvidas no país. Dentro do setor do comércio há o setor varejista, composto na sua maioria por micro e pequenas empresas que são responsáveis pela distribuição final dos produtos acabados. Segundo SEBRAE (2014), as micro e pequenas empresas correspondem a 53,4\% do PIB do comércio e são responsáveis por 52\% dos 
empregos com carteira assinada no país, o que traduz a importância de qualificar e melhorar esses empreendimentos de pequeno porte para a economia brasileira.

O setor varejista engloba diversas subdivisões de distribuição, entre elas está o setor de vestuário, que envolvem variáveis como tendência de moda e sazonalidade, as quais podem ser entendidas como a direção que a moda seguirá a cada temporada (CALDAS, 2004). Tais variáveis influenciam diretamente na compra e venda dos produtos, na tomada de decisões dentro da empresa e consequentemente na gestão de estoque (GARCIA et al., 2006).

A importância da gestão de estoque está na otimização do investimento, contribuindo com impacto positivo no giro do produto, aumentando a eficiência dos meios internos da empresa e diminuindo a necessidade de capital investido, resultando em um melhor equilíbrio entre a oferta e a demanda (LIMA et al., 2015).

Para que as decisões sobre estoque sejam tomadas de maneira segura é necessário que haja registros formais de entradas e saídas de estoques e a maneira mais comum desses registros formais ocorrerem nas empresas é por meio de Sistemas de Informação Gerencial (SIG), que segundo Batista (2004) possibilita a coleta e armazenagem de dados, processando as informações a serem utilizadas na tomada de decisões da empresa. O SIG, embora construído apenas para dar suporte a algumas decisões, pode não conter todas as ferramentas específicas e necessárias para a tomada de decisão. Muitas vezes os relatórios que os SIGs exibem contêm informações estatísticas e sem recursos mais visuais, que facilitam a compreensão. Uma solução para a ausência de alguns artifícios para a tomada de decisão nos SIGs pode surgir com utilização de Sistemas de Suporte à Decisão (SSD), que são sistemas dedicados à escolha de alternativas viáveis, a resolução de problemas e possibilidade de análise de situações mais complexas (TUBAN; VOLONINO; BRODBECK, 2013).

A utilização de metodologias de gestão e controle de estoques é oportuna, e aliada ao estabelecimento de uma estratégia pode ser fundamental para a melhoria do desempenho, acompanhamento de suas ações e sobrevivência dessas empresas.

Dessa forma, o presente estudo tem como objetivo propor uma gestão de estoque por meio da utilização de ferramentas de controle de estoque em uma empresa do setor varejista em IlhéusBA e verificar o impacto destas na tomada de decisão. 


\section{Gestão e controle de estoques}

$\mathrm{Na}$ área logística uma das vertentes fundamentais para o bom desempenho da organização é a gestão de estoque, visto que o estoque é um regulador importante no fluxo de negócios (PASSOS, 2010).

Estoque pode ser definido como um conjunto de bens armazenados, com características próprias, para atender aos objetivos e necessidades da empresa, atuando como um amortecedor entre as variações de oferta e demanda, corrigindo as instabilidades (IZEL; GALVÃO; SANTIAGO, 2015). Para Slack, Chambers e Johnston (2009) o estoque é o acumulo dos recursos materiais dentro do sistema de transformação.

A gestão de estoques auxilia na otimização do investimento realizado, impacta positivamente o giro do produto, aumenta a eficiência dos meios internos da empresa e diminui a necessidade de capital investido, realizando um equilíbrio entre oferta e demanda (LIMA et al., 2015).

As principais decisões na gestão de estoque estão relacionadas à: quanto pedir, observando as demandas futuras; quando pedir, considerando o momento em que o pedido atende a real necessidade da empresa; com que frequência analisar níveis de estoque; onde localizar o estoque e por último como controlar todo o sistema (GARCIA et al., 2006).

Para as decisões relacionadas à gestão de estoques é oportuno utilizar métodos de controle como forma de organizar e identificar disponibilidades de produtos. Isso consiste em: registrar, fiscalizar e gerir as entradas e saídas de insumos e produtos acabados (PASSOS, 2010).

O controle de estoque funciona de forma a estabelecer um nível de equilíbrio entre as necessidades e a obtenção de produtos Portanto controlar o fluxo de produtos é fundamental para a empresa visto que estoque e armazenamento representa parte dos custos que quando inutilizados poderiam ser investidos em outros fins (VENDRAME, 2008; IZEL; GALVÃO; SANTIAGO, 2015). Se a demanda do estoque for maior que o tempo de ressuprimento pode ocorrer prejuízo nas vendas ou na produção. Entretanto, o incorreto dimensionamento pode causar excesso de materiais avariados.

Um das formas de se estabelecer um correto dimensionamento sem que haja falta é ter um estoque mínimo estabelecido. O estoque mínimo é a quantidade suficiente para atendimento enquanto o ressuprimento é feito. O estoque mínimo é calculado a partir do venda média mensal dividida pelo tempo de ressuprimento, conforme demonstrado em (1) (LUSTOSA et al.,2008). 


$$
\text { Estoque Mínimo }=\frac{\text { Venda média mensal }}{\text { Tempo de ressuprimento }}
$$

Para a constância das operações é necessário que haja um fluxo perene de informações sobre compras, recebimento, armazenagem e distribuição, e também que se trabalhe com um planejamento que minimize o custo total (SLACK; CHAMBER; JOHSTON, 2009).

Para isso, pode-se utilizar ferramentas de controle de estoque que funcionem como medidores de desempenho e proporcionem uma melhor análise desse estoque. Entretanto a simples utilização das ferramentas não garante toda análise e gerenciamento adequado, faz-se necessário que o gestor possua capacidade de agrupar essas informações para a tomada de decisão, baseandose na estratégia previamente definida (SLACK; CHAMBER; JOHNSTON, 2009).

\subsection{Ferramentas de controle de estoque}

A próxima seção detalhará algumas das ferramentas utilizadas para controle de estoque como a Curva ABC, o Giro de Estoque e o Diagrama de Pareto.

\subsubsection{Curva ABC}

Todo estoque que armazena mais de um produto, possui produtos com diferentes taxas de uso e diferentes valores. Desde modo, o que se percebe é que os produtos possuem graus de importância diferentes entre si. A falta de algum item pode afetar diretamente os consumidores (SLACK; CHAMBER; JOHNSTON, 2009).

Slack; Chamber e Johnston (2009) afirmam ainda que a forma mais comum de controle de produtos é através do uso da classificação $\mathrm{ABC}$, fazendo a listagem dos produtos de acordo com suas movimentações de valor. A classificação ABC é uma ferramenta importante que auxilia no tratamento adequado da administração dos produtos.

Para Braga, Pimenta e Vieira (2008) a curva ABC classifica os produtos em três classes, conforme pode ser observado também na Figura 1:

- Classe A: formada por $10 \%$ a $20 \%$ dos produtos que possuem valor de consumo acumulado alto (acima de $50 \%$ ate $80 \%$ );

- Classe B: formada por $20 \%$ a $30 \%$ dos produtos com valor de consumo acumulado entre $20 \%$ a $30 \%$;

- Classe C: formada por mais de $50 \%$ dos produtos, os quais possuem consumo acumulado de $5 \%$ a $10 \%$. 
Para a curva $\mathrm{ABC}$ é necessário listar todos os produtos que compõe o estoque indicando o seu valor unitário, a quantidade vendida no período analisado e o valor total por produto. Após isso deve-se organizar os itens em ordem decrescente de valor total e somar o valor total vendido. Em seguida dividindo o valor total de cada produto pelo valor total vendido tem-se a participação de cada produto no valor total vendido, o qual será usado para classificar os produtos em A, B ou C (VENDRAME, 2008).

Figura 1 - Exemplo de Classificação ABC de Estoques

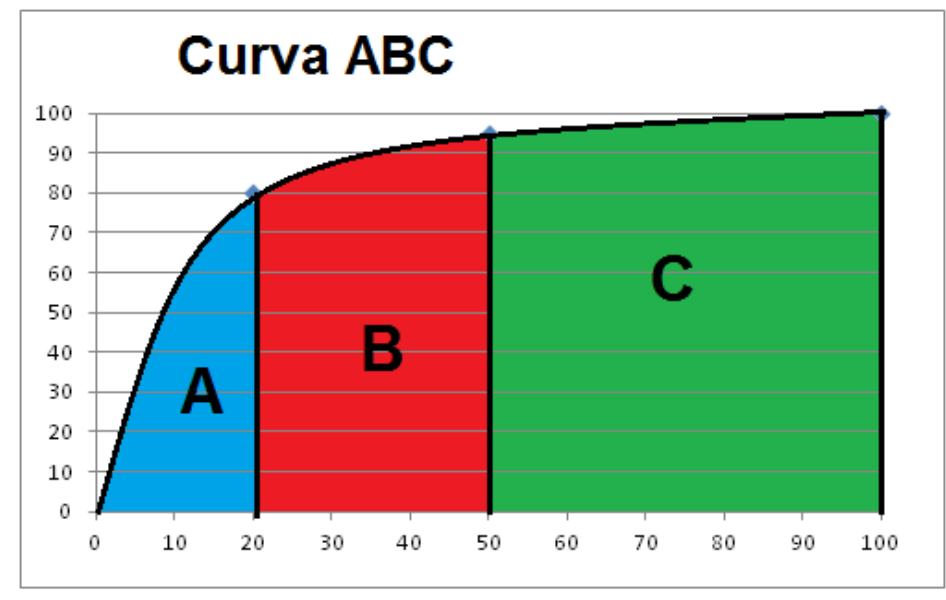

Fonte: Autoria própria (2016)

\subsubsection{Giro de Estoque}

O Giro de Estoque é uma ferramenta de controle que indica quantas vezes o estoque se renovou em sua totalidade, em geral em um período de um ano, o que permite um maior controle sobre saídas e entradas dos produtos no seu mercado (SANTOS et al., 2012).

Quando se trabalha com um giro de estoque alto, consequentemente o nível de estoque é baixo, este fato para algumas empresas podem sinalizar um controle eficiente dos recursos, mas também em alguns casos podem resultar em falta de itens, perda de venda e prejuízos para o negócio (PICK; DIESEL; SELLITTO, 2011). Assim sendo, segundo Dentz (2016) se os índices de giro são interpretados da seguinte forma: se o índice for maior que um - a empresa vendeu mais do que tinha em estoque para o período; se o índice for igual a um, significa que a empresa vendeu todos os itens armazenados para o período; se o índice for menor que um, a empresa não vendeu todos os itens armazenados para o período.

Outro ponto a ser observado é que o alto índice de rotação dos estoques está relacionado com a redução da necessidade de investimento em capital de giro. Outro fato é a obsolescência da mercadoria, que quanto maior o giro, menor a obsolescência (SANTOS et al., 2012). 
De acordo com Martins e Laugeni (2006) o giro é calculado a partir do valor consumido no período de tempo em questão dividido pelo valor de estoque médio do mesmo período, conforme demonstrado em (2).

Giro de Estoque $=\frac{\text { Itens vendidos no periodo }}{\text { Estoque médio do periodo }}$

\subsubsection{Diagrama de Pareto}

O Diagrama de Pareto é uma técnica de análise de causas e envolve classificar itens, conforme ordem de importância podendo destacar áreas que devem ter maior atenção, destacando o que se deve se dar mais importância, além de permitir que seja estabelecido metas numéricas a serem alcançadas (SLACK; CHAMBER; JOHNSTON, 2009).

O Diagrama de Pareto irá auxiliar na priorização de produtos no sistema como um todo, juntamente com a classificação de acordo com a sua relevância com base no uso da classificação ABC (GARCIA et al, 2006). O gráfico destacará para quais erros ou atividades são necessários ações de melhorias.

Para construção do Diagrama de Pareto é preciso que se colete os dados, os quais serão analisados, produção ou venda, realizar o tabelamento e o percentual individual e acumulado de cada situação. A partir dos dados, o diagrama é projetado no gráfico de barras verticais, conforme pode ser observado na Figura 2.

Figura 2 - Exemplo de Diagrama de Pareto

\section{Diagrama de Pareto}

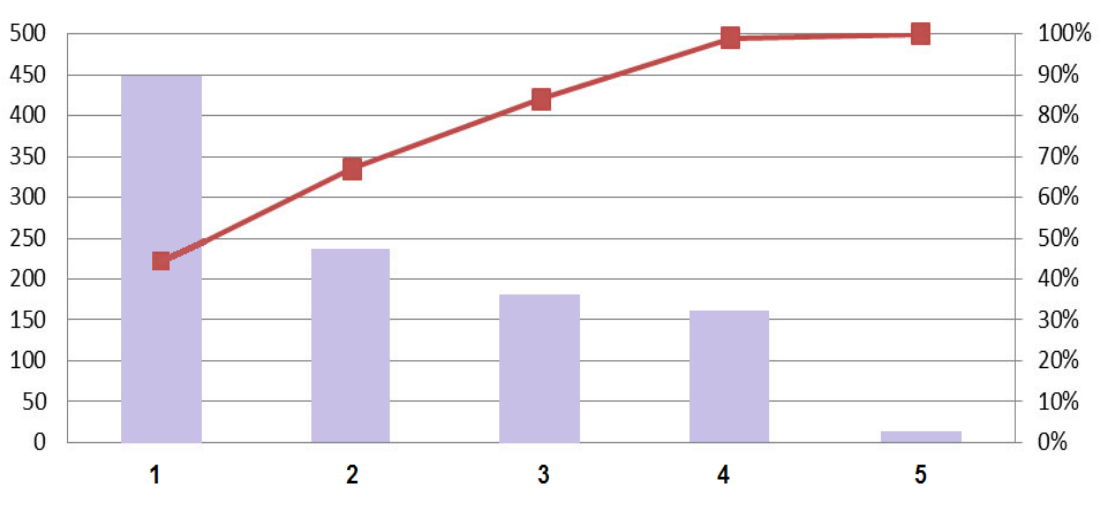

Fonte: Autoria própria (2016) 


\section{Metodologia}

Para construção do artigo, realizou-se uma pesquisa de natureza básica, exploratória por meio de um estudo de caso, buscando propor uma gestão de estoque por meio da utilização de ferramentas de controle, em uma microempresa varejista situada em Ilhéus-BA.

A primeira etapa da pesquisa consistiu em um refinamento da literatura fundamental a compreensão da importância do controle de estoque e suas ferramentas para a delimitação estratégica para a empresa. Em seguida, analisou-se o perfil da empresa varejista de vestuário por meio de visitas técnicas ao local, identificando as variáveis importantes para tomada decisão, tais como a influência da tendência de moda e sazonalidade. Analisou-se também a utilização de um sistema de informação pela empresa, verificando os principais módulos existentes e os tipos de informações disponibilizadas.

Foi realizada a coleta de dados de estoque e de venda, a análise documental por meio do acompanhamento das notas fiscais e a aplicação das ferramentas de controle de estoque (curva $\mathrm{ABC}$, giro de estoque e o Diagrama de Pareto). Os resultados foram tratados por meio do software Microsoft Excel 2007, apresentados e uma proposta para a gestão de estoques foi elaborada para a empresa estudada.

\section{Resultados e discussão}

\subsection{Caracterização da empresa}

A empresa analisada atua no segmento de varejo de vestuário e acessórios da linha surfware e está localizada cidade de Ilhéus, no sul da Bahia. Este segmento está bem consolidado na cidade, que por ser litorânea é referência na prática e no incentivo do surf. Possui 23 anos de existência concorrendo com mais de dez empresas do mesmo segmento na cidade.

A empresa está situada no centro da cidade, possuindo três funcionários e cerca de 650 clientes ativos, uma linha de 24 produtos e mais de 110 fornecedores, o que possibilita uma ampla faixa de variedade e preço para atender diferentes tipos de clientes.

A estratégia da empresa em nível de negocio é o enfoque, já que se dedica a atuar especificamente a um nicho, planejando suas competências essenciais como variedade e preço para atender as necessidades dos seus clientes, buscando um melhor posicionamento de mercado.

As variáveis que envolvem o setor de vestuário nessa empresa influenciam da seguinte forma: a sazonalidade implica nas variações de demanda que tem altos picos nos mês de dezembro e junho e cresce próximo a datas comemorativas; a tendência de moda influencia com base na 
estação, outono/inverno e primavera/verão, com recebimento de peças em cores mais frias e tecidos mais quentes na primeira e cores mais vibrantes e tecidos mais leves na segunda; e influência das semanas de moda, com novas costuras, novos cortes do tecido e mudanças de conceito.

Atualmente a empresa realiza de dois a quatro pedidos por ano, já que a reposição do estoque depende diretamente do lançamento das coleções dos fornecedores e conforme informado pelo proprietário raramente há problemas com tempo de entrega. Devido à ampla variedade de cores e marcas, para garantir a satisfação do cliente, a empresa possui alto estoque de segurança, o que resulta em estoque obsoleto formado por muitas coleções anteriores. As compras com os fornecedores possuem lote mínimo, o que contribui ainda mais para o estoque obsoleto, e ocorre de forma direta, na qual o proprietário escolhe peça por peça do mostruário que irá adquirir, analisando qualidade do tecido e estamparia. No momento da pesquisa a empresa possuía 8500 peças em estoque.

A empresa gerenciava as entradas e saídas de estoque de maneira informal, por meio da vivência diária dos atendimentos, sem a utilização de sistema de informação ou outras formas de registro. No ano de 2015 após perceber a importância de se ter registros e da necessidade de acompanhar de maneira formal o estoque, e compreendendo o impacto nos custos, a empresa passou a utilizar um sistema de informação gerencial, Sistema Integral Comercial - SIC. Utilizou-se para a análise um período de cinco meses (dezembro, janeiro, fevereiro, março e abril de 2016), uma vez que o SIC foi recém-implantado.

\subsection{Sistema de informação utilizado}

O Sistema Integrado Comercial - SIC é um sistema de informação gerencial, implantado pela empresa por escolha do proprietário considerando valores de aquisição e de manutenção, além de indicação por parte de outros varejistas. O sistema possui módulos de vendas, financeiro e de controle de estoque, os quais possibilitam o cadastro de clientes e fornecedores, emissão de notas fiscais, relatórios de entradas e saídas de produtos, realizando somente a coleta e armazenagem de dados, não possuindo ferramentas de análise decisórias.

Como o SIC é um SIG, mas não possui nenhuma funcionalidade para tomada de decisão. Por conta desta deficiência optou-se pela utilização de ferramentas de controle de estoque, para que estas atuassem como métricas e informações de apoio à tomada de decisão.

\subsection{Utilização de ferramentas para controle de estoque}

Para tanto, construiu-se a Classificação ABC, o Giro de Estoque e Diagrama de Pareto de forma a analisar o comportamento dos produtos da empresa. 


\subsubsection{Classificação $\mathrm{ABC}$}

Foi usada a classificação ABC para organizar e classificar as informações de vendas coletados pelo software implantado referente ao período de cinco meses. A Tabela 1 apresenta todos os produtos oferecidos pela empresa, os quais estão classificados conforme as suas respectivas movimentações de valor monetário e percentual no período de cinco meses.

Tabela 1 - Tabela da classificação ABC

\begin{tabular}{|c|c|c|c|c|c|}
\hline Produto & \multicolumn{2}{|l|}{ Valor } & $\%$ & \%acum & Classif \\
\hline Bermuda Praia & $\mathrm{R} \$$ & $86.686,96$ & $23,99 \%$ & \multirow{6}{*}{$\begin{array}{l}23,99 \% \\
38,84 \% \\
45,72 \% \\
52,55 \% \\
58,62 \% \\
64,64 \% \\
\end{array}$} & \multirow[t]{6}{*}{$\mathbf{A}$} \\
\hline Camisa gola careca & $\mathrm{R} \$$ & $53.660,52$ & $14,85 \%$ & & \\
\hline Sandália & $\mathrm{R} \$$ & $24.857,01$ & $6,88 \%$ & & \\
\hline Bermuda Walk & $\mathrm{R} \$$ & $24.675,60$ & $6,83 \%$ & & \\
\hline Mochila & $\mathrm{R} \$$ & $21.935,32$ & $6,07 \%$ & & \\
\hline Camisa Regata & $\mathrm{R} \$$ & $21.757,50$ & $6,02 \%$ & & \\
\hline Infantil & $\mathrm{R} \$$ & $20.896,95$ & $5,78 \%$ & \multirow{7}{*}{$\begin{array}{l}70,42 \% \\
74,36 \% \\
77,95 \% \\
81,35 \% \\
84,54 \% \\
87,11 \% \\
89,66 \% \\
\end{array}$} & \multirow[t]{7}{*}{ B } \\
\hline Relógio & $\mathrm{R} \$$ & $14.207,56$ & $3,93 \%$ & & \\
\hline Camisa gola polo & $\mathrm{R} \$$ & $12.973,19$ & $3,59 \%$ & & \\
\hline Camisa gola V & $\mathrm{R} \$$ & $12.286,26$ & $3,40 \%$ & & \\
\hline Óculos & $\mathrm{R} \$$ & $11.539,51$ & $3,19 \%$ & & \\
\hline Boné & $\mathrm{R} \$$ & $9.295,86$ & $2,57 \%$ & & \\
\hline Tênis & $\mathrm{R} \$$ & $9.194,33$ & $2,54 \%$ & & \\
\hline Calça & $\mathrm{R} \$$ & $8.953,02$ & $2,48 \%$ & \multirow{2}{*}{$\begin{array}{l}92,14 \% \\
94,11 \%\end{array}$} & \\
\hline Sunga & $\mathrm{R} \$$ & $7.137,27$ & $1,98 \%$ & & \multirow[t]{6}{*}{ C } \\
\hline Acessório surf & $\mathrm{R} \$$ & $6.627,50$ & $1,83 \%$ & \multirow{5}{*}{$\begin{array}{l}95,94 \% \\
97,12 \% \\
97,79 \% \\
98,43 \% \\
98,97 \%\end{array}$} & \\
\hline Short & $\mathrm{R} \$$ & $4.238,47$ & $1,17 \%$ & & \\
\hline Carteira & $\mathrm{R} \$$ & $2.416,16$ & $0,67 \%$ & & \\
\hline Parafina & $\mathrm{R} \$$ & $2.342,46$ & $0,65 \%$ & & \\
\hline Pochete & $\mathrm{R} \$$ & $1.940,81$ & $0,54 \%$ & & \\
\hline Cueca & $\mathrm{R} \$$ & $1.867,66$ & $0,52 \%$ & \multirow{4}{*}{$\begin{array}{r}99,49 \% \\
99,72 \% \\
99,96 \% \\
100,00 \% \\
\end{array}$} & \\
\hline Meia & $\mathrm{R} \$$ & 852,93 & $0,24 \%$ & & \\
\hline Cinto & \multirow{2}{*}{$\begin{array}{l}\mathrm{R} \$ \\
\mathrm{R} \$\end{array}$} & \multirow{2}{*}{$\begin{array}{c}843,88 \\
149,90\end{array}$} & $0,23 \%$ & & \\
\hline Feminino & & & $0,04 \%$ & & \\
\hline
\end{tabular}

Fonte: Autoria própria (2016)

A Figura 3 apresenta a curva da classificação ABC vista na Tabela 1, no eixo vertical verifica-se a porcentagem de faturamento de cada grupo e no eixo horizontal verifica-se a porcentagem de produtos pertencentes a esse grupo.

Figura 3 - Curva $\mathrm{ABC}$ dos produtos 


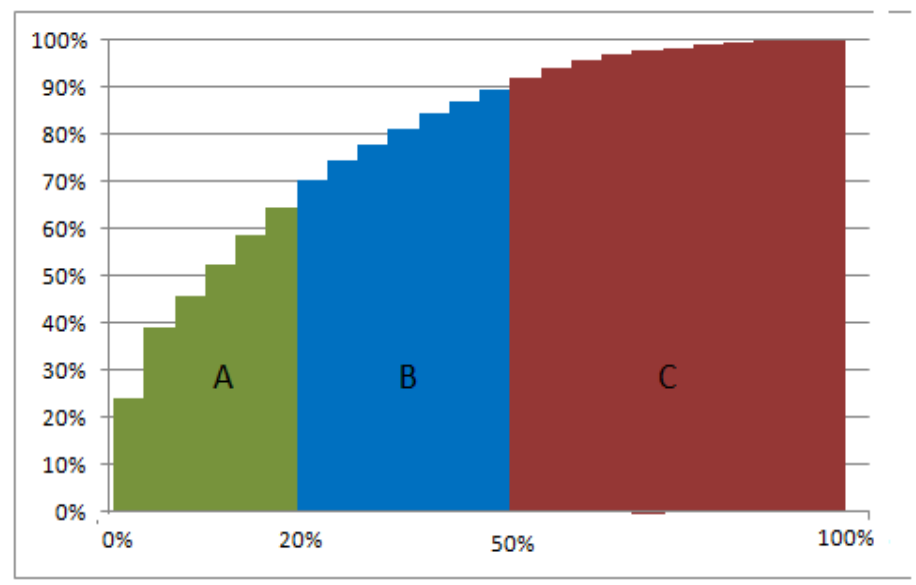

Fonte: Autoria própria

Por meio do arranjo dos produtos na Curva $\mathrm{ABC}$ nota-se quais são os produtos mais aceitos pelo mercado da empresa, classe A e quais possuem a menor parcela de participação, classe C.

A classe A é formada por $20 \%$ dos produtos, e representa, aproximadamente, $70 \%$ do faturamento da empresa que para este caso específico contemplam as bermudas praia, camisas gola careca, sandálias, bermudas walk, mochilas e camisa regatas; a classe B é composta por 30\% dos produtos e representa $20 \%$ do faturamento da empresa que são os produtos infantis, os relógios, as camisas gola polo, as camisas gola em V, os óculos, os bonés e os tênis. Já a classe C é formada por $50 \%$ dos produtos e representam apenas $10 \%$ do faturamento da empresa.

Os itens B são produtos que precisam ser monitorados constantemente, pois se gerenciados de forma estratégica em resposta ao mercado podem potencializar os lucros da empresa. Já os itens C, apesar de não apresentarem perspectivas de crescimento, são estrategicamente importantes, pois são elementos adicionais à compra do cliente, na maioria das vezes são vendidos em "compras casadas" (itens que são comprados em conjunto ao se adquirir algum produto), e acrescentam ao montante final, sendo vantajoso manter pequenos estoques para atender potenciais demandas.

Portanto, os itens A são os produtos que possuem alta participação de mercado, sendo os impulsionadores da empresa e que garantem a lucratividade do negócio. Entretanto, é importante monitorar esses produtos para não criar estoques desnecessários e avaliar qual o impacto dos fornecedores para essa classificação.

\subsubsection{Giro de estoque e Diagrama de Pareto}

Apesar da classificação dos produtos apresentada anteriormente, é importante calcular individualmente quantas vezes o estoque de um determinado produto se renovou na sua totalidade, entendendo qual o giro do produto para um maior controle sobre saídas e entradas no mercado evitando a ocorrência de obsolescência dos produtos (SANTOS et al., 2012). 
Sabe-se também que cada produto possui uma grande lista de fornecedores que devem ser avaliados de forma que os de baixa saída não causem custos desnecessários com estoque parado e que os de alta saída possam ter o relacionamento explorado de maneira mais estratégica a fim de conquistar melhores condições de preços e posição no mercado. O Diagrama de Pareto auxiliará nesta análise

Dessa forma, escolheram-se os produtos classificados como A para aplicar o giro de estoque e o Diagrama de Pareto, por entender que estes representam a maior participação de mercado e consequentemente a maior porcentagem de lucro da empresa e que devido a isso requerem maior atenção para tomada de decisões de investimentos.

\subsubsection{Bermuda praia}

Ao final do período avaliado o produto bermuda praia vendeu 647 peças, mas ainda possuía em estoque 1580 peças, ou seja, vendeu 0,3 (30\%) do seu estoque em cinco meses, o que indica baixo giro de estoque e alto investimento desnecessário feito pela empresa. O procedimento indicado nesse caso seria não realizar mais compras, devido à quantidade de estoque suprir a média de vendas do período. Entretanto por se tratar de um segmento de vestuário, sofre influência de moda e tendências que determinam as necessidades dos clientes, o que impede a não realização de compras, pois a empresa necessita atender as demandas através das novas coleções.

Nesse caso o melhor posicionamento estratégico é analisar quais peças pertencem a antigas coleções e realizar ações de movimentação do produto, evitando obsolescência. Outra estratégia alinhada às movimentações é a análise individual dos 33 fornecedores de forma a realizar compras mais concentradas e com maior variedade.

A Figura 4 apresenta os diversos fornecedores dos itens classificados como A, entre eles os fornecedores de bermuda praia (4a), bem como o quanto cada um vendeu quantitativamente e o percentual acumulado de vendas no período de cinco meses.

Por meio da Figura 4.a é possível perceber que dos 33 fornecedores de bermuda praia, 13 correspondem a $89,95 \%$ das vendas realizadas desse produto, sendo que quatro desses fornecedores compõe 50,23\% do total das vendas. Tais valores demonstram que há uma clara preferência dos clientes pelas marcas 0039, 0041, 0050 e 0047 e que há mais fornecedores do que o necessário para atender a demanda de vendas. Deve-se manter um relacionamento de parceria com essas marcas mais vendidas de forma a concentrar os pedidos e conseguir melhores condições de compras e barganhas. 
Figura 4 - Diagrama de Pareto dos diversos fornecedores para os itens A

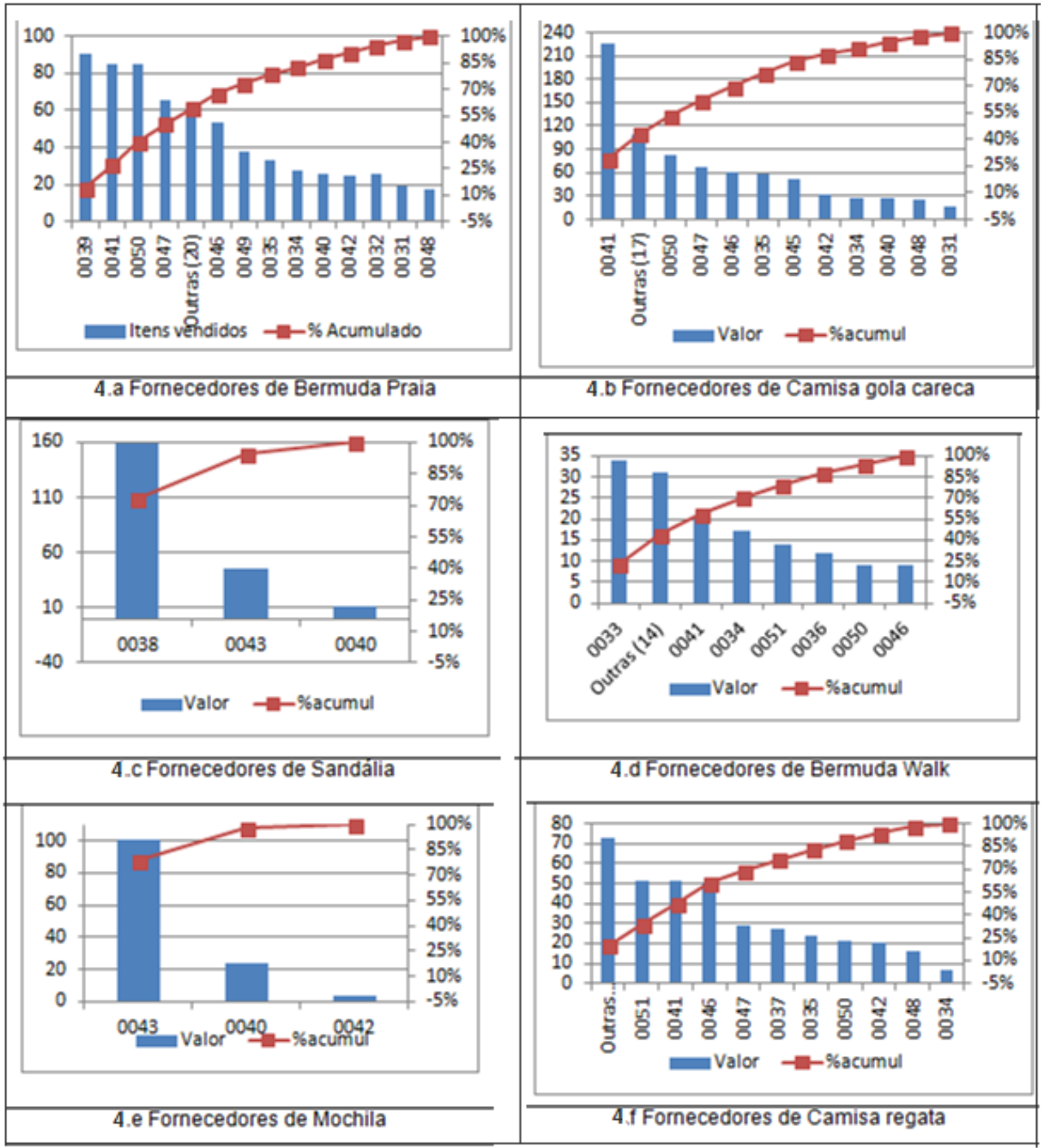

Fonte: Autoria própria (2016)

\subsubsection{Camisa gola careca}

O produto camisa gola careca no período avaliado havia vendido 784 peças e ainda possuía em estoque 644 peças, ou seja, vendeu 0,5 (50\%) do estoque em cinco meses, o que indica baixo giro de estoque e alto investimento desnecessário feito pela empresa. 
Nesse caso a empresa deve analisar os produtos, classificando se eles estão alinhados com a tendência das novas coleções de forma a realizar ações de movimentação, com os produtos não alinhados, como liquidação ou venda para outras empresas. Outra estratégia é analisar o comportamento de vendas dos 28 fornecedores de forma a realizar compras mais concentradas e com maior variedade.

A Figura 4.b apresenta os fornecedores de camisa gola careca, bem como o quanto cada um vendeu quantitativamente e o percentual acumulado de vendas no período de cinco meses.

Analisando a figura 4.b é possivel perceber que dos 28 fornecedores de camisa gola careca, 11 correspondem a $85,97 \%$ das vendas realizadas e mais da metade das vendas correspondem os fornecedores 0041, 0050, 0047 e 0046. Percebe-se também que 22 fornecedores tem contribuição menor de $5 \%$ o que indica que o número de fornecedores para esse produto pode ser reduzido para ampliar a economia por aumento do lote.

\subsubsection{Sandália}

O produto sandália no período avaliado havia vendido 217 peças e ainda possuía em estoque 596 peças, ou seja, vendeu $0,36(36 \%)$ do seu estoque em cinco meses, o que indica o alto investimento desnecessário feito pela empresa.

Como sandália também é um produto que sofre influência de moda e tendência é aconselhado uma verificação de quais pares pertencem a coleções antigas e realizar liquidações para movimentar o produto ou parceria com outras empresas que vendam o mesmo produto e evitar que a obsolescência impacte na depreciação do produto. Além disso, é importante a análise individual dos três fornecedores para melhor distribuir a quantidade a ser comprada.

A Figura 4.c apresenta os fornecedores de sandálias, bem como o quanto cada um vendeu quantitativamente e o percentual acumulado de vendas no período de cinco meses.

Analisando a Figura 4.c nota-se que um fornecedor é o principal responsável pelas vendas, entretanto por ter três fornecedores para administrar é vantajoso mantê-los para garantir a variedade de opções. O cuidado deve ser com a taxa de compras que deve ser distribuída conforme as diferentes demandas de cada um. 


\subsubsection{Bermuda walk}

No período avaliado, o produto bermuda walk havia vendido 147 peças e ainda possuía em estoque 508 peças, ou seja, vendeu 0,29 (29\%) do seu estoque em cinco meses, a menor taxa de giro entre os produtos da classe $\mathrm{A}$, o que indica novamente o alto investimento desnecessário feito pela empresa.

O posicionamento da empresa nesse caso deve visar a movimentação do produto, a fim de evitar que a depreciação do produto seja grande. A realização de ações de movimentação como liquidação ou parceria com empresas do mesmo segmento alinhada a analise dos 21 fornecedores para direcionar melhor as compras é posicionamento positivo a ser seguido.

A Figura 4.d apresenta os fornecedores de bermuda walk, bem como o quanto cada um vendeu quantitativamente e o percentual acumulado de vendas no período de cinco meses.

Por meio da Figura 4.d percebe-se que dos 21 fornecedores, sete representam 78,91\% das vendas realizadas e aproximadamente metade das vendas correspondem aos fornecedores 0033 , 0041 e 0034. A empresa deve aumentar seu lote de compra com esses fornecedores de forma a conseguir melhores condições de compras e aumento da variedade além de diminuir a sua cartela de fornecedores.

\subsubsection{Mochila}

Ao final do período avaliado, o produto Mochila havia vendido 128 peças e ainda possuía em estoque 33 peças, ou seja, vendeu $0,8(80 \%)$ do estoque em cinco meses, o que indica um giro próximo do adequado considerando que foi analisado meses correspondentes ao inicio do ano que há maior venda devido ao período de férias e volta às aulas.

Nesse caso a empresa deve manter o seu posicionamento de compras, analisando demandas anteriores para aumentando o giro do produto e analisar o relacionamento com os seis fornecedores.

A Figura 4.e apresenta os fornecedores de Mochila, bem como o quanto cada um vendeu quantitativamente e o percentual acumulado de vendas no período de cinco meses.

Analisando a Figura 4.e nota-se que houveram saídas somente de três fornecedores do total dos seis e que um fornecedor é o principal responsável pelas vendas do produto. Com base nesse cenário é importante que seja reduzido para 2 o número de fornecedores de mochilas na tentativa da economia por lote e realizar promoções com os produtos dos fornecedores que já estão a mais de 5 meses no estoque, evitando uma maior depreciação dos produtos. 


\subsubsection{Camisa regata}

O produto camisa regata ao final do período avaliado havia vendido 369 peças e ainda possuía em estoque 201 peças, ou seja, vendeu 0,6 (60\%) do estoque em cinco meses, o que indica um giro baixo.

Nesse caso a empresa deve diminuir a quantidade de compras, considerando a variação sazonal do produto, tentando sempre diminuir a quantidade para evitar obsolescência dos produtos. Outra estratégia é analisar o comportamento de vendas dos 26 fornecedores de forma a realizar compras mais concentradas e com maior variedade.

A Figura 4.f apresenta os fornecedores de camisa regata, bem como o quanto cada um vendeu quantitativamente e o percentual acumulado de vendas no período de cinco meses.

Analisando a Figura 4.f é possível perceber que dos 26 fornecedores de camisa regata, 10 correspondem a $80,22 \%$ das vendas realizadas e aproximadamente metade das vendas correspondem os fornecedores 0051, 0041, 0046 e 0047. Portanto é possível concentrar suas compras em poucos fornecedores mantendo a variedade e o atendimento satisfatório dos clientes.

\subsection{Avaliação das ferramentas de controle de estoque}

Após a análise dos seis produtos classificados como A, percebe-se que a falta de uma gestão de estoque prejudicou os investimentos da empresa, que realizava compras sem análise, que geraram obsolescência e depreciação dos produtos.

Foi possível notar que os fornecedores mais vendidos: 0041, 0050, 0047 e 0046 são praticamente os mesmos entre os produtos mais vendidos, o que indica que o relacionamento e poder de barganha podem e devem ser melhor explorados por parte da empresa, a fim de conseguir condições apropriadas de compras e oferecer melhores condições de venda aos seus clientes.

A maioria dos produtos possuem níveis de estoques suficientes para o ano todo conforme a média de vendas do período analisado. Entretanto por se tratar de um segmento de vestuário, sofre influência de moda e tendências que determinam as necessidades dos clientes, há a necessidade da realização de novos pedidos para atender a demanda de um segmento exigente de clientes que compõe esse setor.

De forma a não ocorrer obsolescência e depreciação, é importante a constante movimentação dos produtos, mantendo números de giro de estoque conforme a quantidade de pedidos feitos, por isso foi indicado em quase todos os casos a realização de ações de movimentação do produto. Essas ações de movimentação poderiam ser parceria com empresas do mesmo segmento para troca de produtos ou liquidação, a qual é um conjunto de ações que 
proporcionam a venda dos produtos, aumentando o giro de estoque, maximização dos investimentos que são sustentados pelo planejamento e remarcação de preços (CASTRO, 2014). O planejamento deve ser feito visando o equilíbrio, as peças vendidas normalmente no período devem ter preços com lucro máximo (PINDYCK; RUBINFELD, 2002) e as peças vendidas em liquidação devem ter os preços baseados nas somas dos custos com margem de retorno, com preço de equilíbrio (NEVES; VICECONTI, 2013).

Portanto, a utilização de ferramentas de controle de estoque pode proporcionar uma visualização do conjunto de produtos de forma específica e individual. Ao adotar essa visão as decisões são mais sustentadas e consequentemente há a diminuição da necessidade de capital de giro, que deixa de ser investida em custos com armazenamento de produtos e compras de lotes desnecessários e passa a estar disponível para investimentos em publicidade e ações que atraiam novos clientes e fidelize clientes antigos.

\subsection{Proposta de gestão de estoques}

Com base nos problemas identificados pela a utilização das ferramentas de controle de estoque e visando desenvolver uma melhor estratégia de mercado, realizou-se uma seleção de fornecedores de maneira a eliminar a problemática causada pela alta quantidade desnecessária de fornecedores; uma previsão de demanda e a definição do estoque mínimo e do ressuprimento (Figura10). Para isso, a proposta de gestão de estoque precisa estar alicerçada nos parâmetros elencados por Garcia et al. (2006), que são: o quanto pedir, relacionado a previsão de demanda; quando pedir, referindo-se aos níveis de estoque e ao ressuprimento; uma frequência mensal de se analisar os níveis de estoque de forma a mapear seu comportamento; onde está relacionado a localização do estoque dentro da própria empresa por meio do sistema de informação já existente e o como controlar o sistema pelas informações armazenadas no SIC e também nas ferramentas de controle de estoque, impactantes no monitoramento das ações e comportamento da tendência.

Figura 10: Proposta de Gestão de Estoque

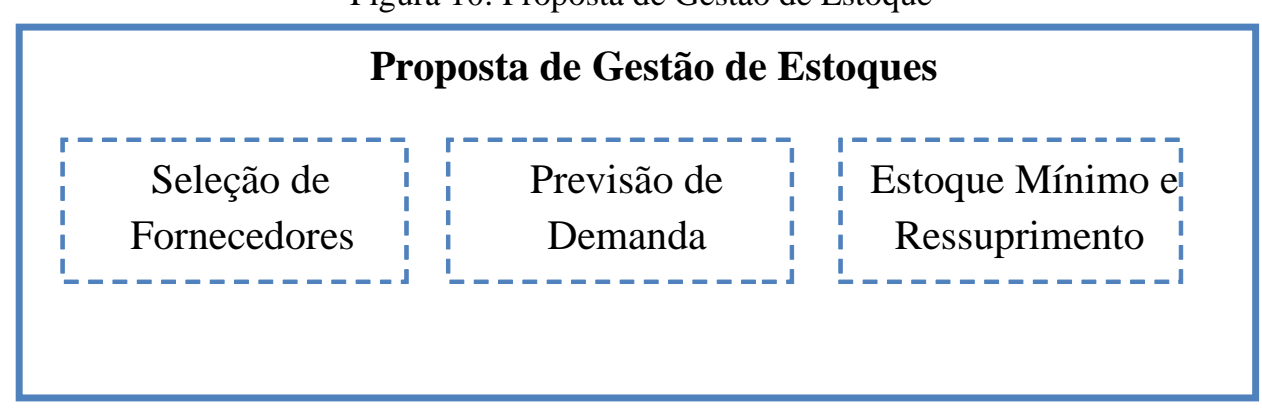

Fonte: Autoria Própria (2016) 


\subsubsection{Seleção de fornecedores}

Como retratado anteriormente, a empresa possui 110 fornecedores e por meio das ferramentas de controle de estoque foi possível concluir que a necessidade da empresa é atendida com muito menos da metade dessa quantidade. Portanto, para a seleção de fornecedores considerou fatores qualitativos e quantitativos. Os fatores quantitativos considerados são: a demanda sobre os produtos daquele fornecedor, a qualidade, preço e capacidade de atender. Já os fatores qualitativos considerados foram: a confiança, a compatibilidade administrativa e o impacto da marca do fornecedor, visto que o mercado de vestuário sofre influência de variáveis como moda, e o consumidor muitas vezes é influenciado a comprar pela marca do produto (FURTADO, 2005).

Devido a cada produto ter uma especificação diferente, os parâmetros foram analisados de forma individual e também analisado os Diagramas de Pareto para cada produto, em que a quantidade ideal corresponde a quantidade de fornecedores que são responsáveis por $80 \%$ das vendas, conforme é apresentado na Tabela 2.

Tabela 2 - Seleção de fornecedores por produto

\begin{tabular}{lcc}
\hline & \multicolumn{2}{c}{ Seleção de Fornecedores } \\
Produto & Quant. Atual & Quant. Ideal \\
Bermuda & 33 & 13 \\
Camisa gola careca & 28 & 11 \\
Sandália & 3 & 3 \\
Bermuda walk & 21 & 7 \\
Mochila & 6 & 2 \\
Camisa regata & 26 & 10 \\
\hline
\end{tabular}

Fonte: Autoria própria (2016)

\subsubsection{Demanda}

A demanda é um importante parâmetro, pois permite a previsão do futuro e possibilita o planejamento de ações de acordo com o cenário (SLACK; CHAMBER; JOHNSTON, 2009). Contudo a empresa não realiza previsão de demanda e só possui registros a partir de dezembro de 2015, o que impossibilita uma previsão de demanda de modo mais assertivo, a qual considere todos os picos durante o ano e influências da sazonalidade. Entretanto, calcular uma prévia possibilita uma base de vendas mínimas que devem ser ajustadas a cada mês e ao final de um ano. Dessa forma foi calculada a demanda por meio da media móvel, a qual é indicada para previsões à curto prazo e com poucos dados (TUBINO, 2000). Ao calcular a previsão por meio da media móvel não se 
considerou outlier nos cálculos por representarem picos de venda específicos daquele período devido a datas comemorativas, conforme é apresentado na Tabela 3.

Tabela 3 - Previsão de demanda por produto

\begin{tabular}{|c|c|c|c|c|c|c|}
\hline \multirow[b]{2}{*}{ Produto } & \multicolumn{5}{|c|}{ Vendas realizadas } & \multirow{2}{*}{$\begin{array}{c}\text { Previsão } \\
\text { Maio }\end{array}$} \\
\hline & Dezembro & Janeiro & Fevereiro & Março & Abril & \\
\hline Bermuda & $471 *$ & 52 & 32 & 53 & 39 & 44 \\
\hline Camisa gola careca & $557 *$ & 68 & 53 & 46 & 60 & 56 \\
\hline Sandália & $74 *$ & 40 & 30 & 30 & 38 & 34 \\
\hline Bermuda walk & $86^{*}$ & 18 & 8 & 4 & 31 & 16 \\
\hline Mochila & 6 & 12 & $73 *$ & 23 & 14 & 13 \\
\hline Camisa regata & $228 *$ & 31 & 35 & 36 & 39 & 35 \\
\hline
\end{tabular}

Fonte: Autoria própria(2016)

\subsubsection{Estoque mínimo e Ressuprimento}

Devido ao fato de se tratar de uma empresa de vestuário e os produtos apresentarem variação de tamanho, cores, modelos e estampas, é necessário que a empresa tenha um nível de estoque que permita a variedade de peças do produto a fim de oferecer opções de escolha ao cliente. Entretanto, esse nível de estoque tem que ser equilibrado constantemente para que não haja obsolescência das peças, uma vez que cada período demandará um nível diferente para atender a demanda existente. Dessa forma os níveis de estoque foram calculados com base no estoque mínimo que a empresa deve ter para realizar pedidos, conforme apresenta a Tabela 4.

Tabela 4 - Nível de estoque por produto

\begin{tabular}{l|cc}
\hline \multicolumn{1}{c|}{ Produto } & $\begin{array}{c}\text { Venda media } \\
\text { mensal }\end{array}$ & Estoque Mínimo \\
Bermuda & 44 & 132 \\
Camisa gola careca & 56 & 168 \\
Sandália & 34 & 102 \\
Bermuda walk & 16 & 48 \\
Mochila & 13 & 39 \\
Camisa regata & 35 & 105 \\
\hline
\end{tabular}

O ressuprimento em empresa de vestuário ocorre conforme o lançamento das coleções das marcas dos fornecedores, de forma a sempre haver variedade e novidades. Portanto com base na seleção dos fornecedores e na previsão de demanda, o ressuprimento deve permanecer de 2 a 4 
vezes ao ano, conforme o lançamento das coleções, entretanto é importante que haja o parcelamento nas entregas que devem ser parceladas baseado nos níveis de estoques.

\title{
5. Conclusão
}

Empresas varejistas buscam variedade e ampla faixa de preço para atender a diferentes segmentos de clientes, dessa forma o presente estudo constatou que a falta de controle de estoque nesse tipo de empresa pode gerar muito prejuízo devido à ausência de informações para tomada de decisão. A alta quantidade de fornecedores contribui para construção de altos níveis de estoques que resultam em obsolescência e depreciação dos produtos, sendo um sinal de má gestão empresarial.

A utilização de ferramentas de controle de estoque contribui satisfatoriamente, pois possibilitou a transformação de dados e informações em indicadores de desempenho que sustentam decisões dentro da empresa e criam um posicionamento estratégico de mercado, o qual é essencial para adaptar-se com segurança as inúmeras variações do mercado. Além disso a utilização das ferramentas contribuiu para elaboração da proposta de gestão de estoque a ser utilizada pela empresa.

Dessa forma, a gestão de estoque contribui com o desenvolvimento das micro e pequenas empresas de comércio, por meio de um melhor direcionamento e suporte na tomada de decisão, culminando também com uma maior taxa de sobrevivência, visto que estas possuem grande importância para o desenvolvimento econômico e social do país.

\begin{abstract}
The retail sector includes several subdivisions, among them are the garment sector, which involves variables such as fashion and seasonal trends, which directly influence the buying and selling of products, generating reflections in decision-making within the company and inventory management. However, many micro and small retailers do not have an information system with decision-making modules and inventory management. Thus, this study aimed to present a proposal for inventory management through inventory control tools in a retail company in Ilheus-BA, to ensure a competitive advantage. The survey took place from the business profile of the study and data collection, which were treated by the set of inventory control tools: ABC Curve, Inventory Turnover and Pareto Diagram. The results were analyzed to establish an inventory management in that impact on competitive market strategy. It was noticed that the lack of management has contributed to accumulation of inventory, depreciation of products and also to misallocation of capital. The preparation of a proposal for inventory management contributes to the development of these micro and small retailers through better targeting and support, also contributing to a higher survival rate, and consequently for economic and social development of the country.
\end{abstract}

Key-words: Inventory Management; Tool Inventory Control; Selection of suppliers; Demand Forecasting; Minimum stock and Resupply 


\section{Referências}

AFF, C. C., DE ARAÚJO, R. M. Móveis planejados: Um estudo sobre a cadeia de fornecimento no contexto da inovação. Revista Eletrônica do Mestrado Profissional em Administração da Universidade Potiguar, 49-62, 2013

BATISTA, Emerson de Oliveira. Sistema de Informação: o uso consciente da tecnologia para o gerenciamento. São Paulo: Saraiva, 2004.

BEHR, A.;MORO, E. L.S. Gestão da biblioteca escolar: metodologias, enfoques e aplicação de ferramentas de gestão e serviços de biblioteca. Ci. Inf., Brasília, v.37, n. 2, p.32-42, maio/ago. 2008

BRAGA, Lilian Moreira; PIMENTA, Carolina Martins; VIEIRA, José Geraldo Vidal. Gestão de armazenagem em um supermercado de pequeno porte. Revista P\&D em Engenharia de Produção, n. 8, p. 57-77, 2008.

CALDAS, Dário. Observatório de Sinais. Teoria e Prática da Pesquisa de Tendências. São Paulo: Senac Nacional, 2004.

CASTRO, Lauro B. L. Discriminação no varejo: maximizando ganhos na liquidação. Revista Uniabeu, n. 17, p 283292,2014

CHIAVENATO, I. Administração de Materiais: uma abordagem introdutória. Rio de Janeiro. 3 Reimp. Elsevier, 2005.

DENTZ, J. C. V. Aprenda como calcular o giro de estoque da sua empresa. Conta Azul. Julho 2016. Disponível em: < https://blog.contaazul.com/giro-de-estoque/>. Acesso em julho 2016

FURTADO, Gustavo Adolfo Pudenci. Critérios de seleção de fornecedores para relacionamentos de parceria: um estudo em empresas de grande porte [online]. São Paulo: Faculdade de Economia, Administração e Contabilidade, Universidade de São Paulo, 2005. Dissertação de Mestrado em Administração.

GARCIA, E.; REIS, L.; MACHADO, L.; FERREIRA FILHO, V.J. Gestão de estoques: otimizando a logística e a cadeia de suprimentos. Rio de Janeiro: E-papers, 2006.

HITT; Michael A. IRELAND; Duane, HOSKISSON; Robert E. Administração Estratégica. Tradução da $7^{\circ}$ edição norte americana. $2^{\circ}$ ed. Cengage Learning. 2007.

IZEL, P. A.; GALVÃO, A. U. R.; SANTIAGO, S. B.; Gestão de estoque: estudo de caso em uma distribuidora de lubrificantes em Manaus. In: ENCONTRO NACIONAL DE ENGENHARIA DE PRODUÇÃO, 25.,2015, Fortaleza. Anais eletrônicos... Fortaleza, CE, 2015. Disponível em:

<http://www.abepro.org.br/biblioteca/TN_STO_206_222_27985.pdf> Acesso em: 19 de jan 2016.

KOXNE, Daniele Comandoli; HAUSSMANN, Darclê Costa Silva; BEUREN, Ilse Maria. Um Estudo do Controle e dos Custos dos Estoques: o caso de uma empresa comercial varejista importadora. Anais do Simpósio de Excelência em Gesto e Tecnologia SEGET, III, Rio de Janeiro, 2006.

LIMA, E. d., FILION, L. J., DALFOVO, O., JUNIOR, V. U. Gestão estratégica e compartilhamento da visão em micro e pequenas empresas. Revista Ibero-Americana de Estratégia - RIAE, 12-4, 2013.

LIMA, I. D. A.; SILVA, J. C. K.; PIOL, K. D. B.; DINIZ, M. F. S.; FERREIRA FILHO, H. R. Análise da gestão de estoque de matérias-primas utilizadas para produção da merenda escolar: Proposta para otimizar a utilização de recursos em uma escola pública localizada no município de Marabá-PA. In: Simpósio de Engenharia de Produção, 22, 2015, Bauru. Anais eletrônicos..Bauru, SP, 2015. Disponível em: < http://www.simpep.feb.unesp.br/anais simpep.php?e=10>

LUSTOSA, L. J.; MESQUITA, M. A., QUELHAS, O. L. G.; OLIVEIRA, R. J. Planejamento e Controle da Produção. $1^{\circ}$ Ed. Rio de Janeiro: Elsevier, 2008

MARTINS, P. G.;LAUGENI, F. P. Administração da Produção. $2^{\circ}$ Ed. São Paulo: Saraiva, 2005

NEVES, Silvério das; VICECONTI, Paulo E. V. Introdução à Econômica. 12 Edição. São Paulo: Saraiva, 2013. 
OBADIA, I. J.; VIDAL, M. R.; MELO, P. F. Uma abordagem adaptativa de intervenção para mudança organizacional. Gestão e Produção, 125-138, 2007. crossref

PASSOS, L. A. A fragilidade do controle de estoque varejista face à dinâmica mercadológica. Revista Urutágua. Universidade Estadual de Maringá, Maringá, n. 20, jan-abr.,2010.

PORTER, Michael E. Estratégia competitiva: técnicas para análise de indústrias e da concorrência. 2.ed. Rio de Janeiro: Elsevier, 2004

PICK, Valdir Luis; DIESEL, Letícia; SELLITTO, Miguel Afonso. Influência dos sistemas de informação na gestão de estoques em pequenos e médios supermercados. Revista Produção Online, Florianópolis, v. 11, n. 2, p. 319-343, maio 2011. ISSN 16761901. Disponível em: 〈http://www.producaoonline.org.br/rpo/article/view/638/788 >. Acesso em: 27 jan. 2016.

PINDIYCK, Roberto H,RUBINFELD, Daniel L. Microeconomia. 5 Edição. São Paulo: Prentice Hall, 2002.

SANTOS, E. B.; AZEVEDO, P. H. B. M.; BENTES, R. I.; ARAUJO, L. R. T. Análise da utilização de ferramentas de gestão de estoque em uma empresa produtora de bebidas, como auxílio à gestão da logística de materiais em um cenário de demanda variável. In: ENCONTRO NACIONAL DE ENGENHARIA DE PRODUÇÃO, 22.,2012, Bento

Gonçalves.Anais eletrônicos... Bento Gonçalves, RS, 2012. Disponível

em: $<$ http://www.abepro.org.br/biblioteca/enegep2012_TN_STP_157_914_20007.pdf >. Acesso em: 18 de jan 2016

SEBRAE Mato Grosso, 2014. Micro e pequenas empresas geram 27\% do PIB do Brasil. Disponível em:

<http://www.sebrae.com.br/sites/PortalSebrae/ufs/mt/noticias/micro-e-pequenas-empresas-geram-27-do-pib-dobrasil,ad0fc70646467410VgnVCM2000003c74010aRCRD>.Acesso em: 18 de jan 2016

SLACK, N.; CHAMBER, S.; JOHNSTON, R. Administração de Produção. 2. ed. São Paulo: Atlas, 2009

TUBINO, D. F. Manual de Planejamento e Controle da Produção. São Paulo: Atlas, 2000.

TURBAN, Efraim; VOLONINO, Linda; BRODBECK, Ângela Freitag. Tecnologia da informação para gestão: em busca do melhor desempenho estratégico e operacional. 8. ed. Porto Alegre: Bookman, 2013. 468 p

VENDRAME, F. C. Administração de Recursos Materiais e Patrimoniais. Apostila da Disciplina de Administração, Faculdade Salesianas de Lins, 2008.

VIANA, J. J. Administração de Materiais: um enfoque prático. 1 ed 8. Reimpressão. São Paulo: Atlas, 2009.

\section{Dados dos autores:}

\section{$1^{\circ}$ Autor}

Nome completo: Caroline Santa Rosa Souza

Filiação institucional: Universidade Estadual de Santa Cruz

Funçao ou cargo ocupado: Graduanda

Endereço completo para correspondência: Avenida Soares Lopes, 1490-B, Cidade Nova, Ilhéus BA, Brasil - CEP: 45.653-005

Telefones para contato: (73) 99964-0834

Email: carolinesrsouza@gmail.com

\section{$2^{\circ}$ Autor}

Nome completo: Meire Ramalho de Oliveira

Filiação institucional: Universidade Estadual de Santa Cruz

Função ou cargo ocupado: Professora do Colegiado de Engenharia de Produção 
Endereço completo para correspondência: UESC - Campus Soane Nazaré de Andrade - Rod. Jorge Amado, km 16 - Salobrinho, Ilhéus - BA

Telefones para contato: (16) 99228-5465

Email:moliveira@uesc.br

Submetido em:03-10-2016

Aceito em: $31 / 12 / 2016$ 